\title{
A Kinetic Investigation of Ethanol Oxidation on a Nickel Oxyhy- droxide Electrode
}

\author{
I. Danaee ${ }^{\mathrm{a}}$, M. Jafarian ${ }^{\mathrm{b} \dagger}$, M. Sharafi ${ }^{\mathrm{b}}$, F. Gobal ${ }^{\mathrm{c}}$ \\ ${ }^{a}$ Abadan Faculty of Petroleum Engineering, Petroleum University of Technology, Abadan, Iran \\ ${ }^{b}$ Department of chemistry, K. N. Toosi University of Technology, Tehran, Iran \\ ${ }^{c}$ Department of chemistry, Sharif University of Technology, Tehran, Iran
}

\begin{abstract}
:
Nickel modified NiOOH electrodes were used for the electrocatalytic oxidation of ethanol in alkaline solutions where the methods of cyclic voltammetry (CV) and chronoamperometry (CA) were employed. In CV studies, in the presence of ethanol, an increase in the current for the oxidation of nickel hydroxide is followed by a decrease in the corresponding cathodic current. This suggests that the oxidation of ethanol is being catalysed through mediated electron transfer across the nickel hydroxide layer comprising of nickel ions of various valence states. Under the CA regime the reaction followed a Cottrellian behavior and the diffusion coefficient of ethanol was found to be $1 \times 10^{7} \mathrm{~cm}^{2} \mathrm{~s}^{-1}$.
\end{abstract}

Keywords: Ethanol, Electrocatalytic, Nickel, Modified electrode

Received March 18, 2012 : Accepted March 28, 2012

\section{Introduction}

In the past decades, the direct methanol fuel cell (DMFC) has drawn attention for its simple construction with reduced dimensions and high-energy efficiency. Progress has been made in this field. ${ }^{1-3)}$ However, the intrinsic disadvantage of DMFC is the toxicity of methanol. Therefore, researchers have looked for other small molecule alcohols as alternative fuels. ${ }^{4,5)}$ Ethanol has emerged as the first choice because of its non-toxicity and low volatility together with a higher energy density than methanol $(8.01 \mathrm{kWh}$ $\mathrm{kg}^{-1}$ versus $\left.6.09 \mathrm{kWh} \mathrm{kg}^{-1}\right)^{6}$. Other important considerations for choosing ethanol are its low price, natural availability, renewability, a higher power density, zero green-house contribution to the atmosphere and its transportability. Among the published reports on proton exchange membrane fuel cells (PEMFC) with

${ }^{\dagger}$ Corresponding author. Tel.: +98-21-22853551

E-mail address: jafarian@kntu.ac.ir alcohol as fuel, ${ }^{5-9)}$ the direct ethanol fuel cell (DEFC) seems promising, especially for the application in devices like electric vehicles, mobile telephone and laptops. Oxidizable metal Pt and Pt alloy ${ }^{10-12)}$ electrodes provide simple way for the catalytic oxidation of ethanol.

The main difficulty of ethanol application in fuel cells is still the low current density obtained due to the process of self-poisoning promoted by the strongly adsorbed reaction intermediate species on platinum. These species can be $\mathrm{CO}$ or other carbonated species with one or two carbon atoms. ${ }^{13-19)}$ The main intrinsic problem is the strong interaction of the adsorbed intermediates with the active sites of the electrode surface. This makes it necessary to look for the new approaches towards the development of effective anodic catalysts providing the sufficiently high rate and oxidation depth of ethanol. There are certain advantages in using alkaline electrolytes, as their relatively low corrosive activity opens the possibility of using nickel, iron, cobalt, and their oxides. Some of 
the data on ethanol oxidation in an alkaline electrolyte on platinum are presented in work, ${ }^{20)}$ in which the authors observed the strong passivation of platinum and came to the conclusion about the necessity of developing a more acceptable catalyst than platinum. In further works, ${ }^{21,22)}$ ethanol oxidation was studied in $1 \mathrm{M} \mathrm{KOH}$ on titanium promoted by $\mathrm{RuO}_{2} / \mathrm{Ni}$ system and glassy carbon coated by RuNi nanoparticles. The activity of these catalysts was low, and the starting potential of alcohol oxidation was close to $0.9 \mathrm{~V}$ vs. the reversible hydrogen electrode (RHE). Therefore, the development of a catalyst that oxidizes ethanol is of high interest. Electrochemical oxidation of ethanol at nickel electrode was studied by Park et al. ${ }^{23)}$ in $1 \mathrm{~m}$ $\mathrm{KOH}$ solution containing $0.2 \mathrm{M}$ ethanol using electrochemical impedance spectroscopy. The results suggested that the $\beta-\mathrm{Ni}(\mathrm{OH})_{2} / \beta-\mathrm{NiOOH}$ redox couple is acting as an effective electron transfer mediator for ethanol oxidation.

The purpose of the present work is to study the kinetic of oxidation reaction of ethanol on a nickel modified $\mathrm{NiOOH}$ electrode in room temperature in basic solution.

\section{Methods and Materials}

Sodium hydroxide and ethanol used in this work were Merck products of analytical grade and were used without further purifications. Doubly distilled water was used throughout.

Electrochemical studies were carried out in a conventional three electrode cell powered by an electrochemical system comprising of EG\&G model 273 potentiostat/galvanostat. The system is run by a PC through M270 commercial softwares via a GPIB interface. A dual Ag/AgCl-Sat'd $\mathrm{KCl}$, a Pt wire and a nickel disk electrode were used as the reference, counter and working electrodes, respectively. All studies were carried out at $298 \pm 2 \mathrm{~K}$.

The nickel disk electrode was polished with $0.05 \mathrm{~mm}$ alumina powder on a polishing micro-cloth and rinsed thoroughly with doubly distilled water prior to modification. Cyclic voltammetry from 0-0.6 V vs. $\mathrm{Ag} / \mathrm{AgCl}$ with 50 cycles was used for electrode surface modification and activation. ${ }^{24)}$

\section{Results and discussion}

Fig. 1 presents consecutive cyclic voltammograms

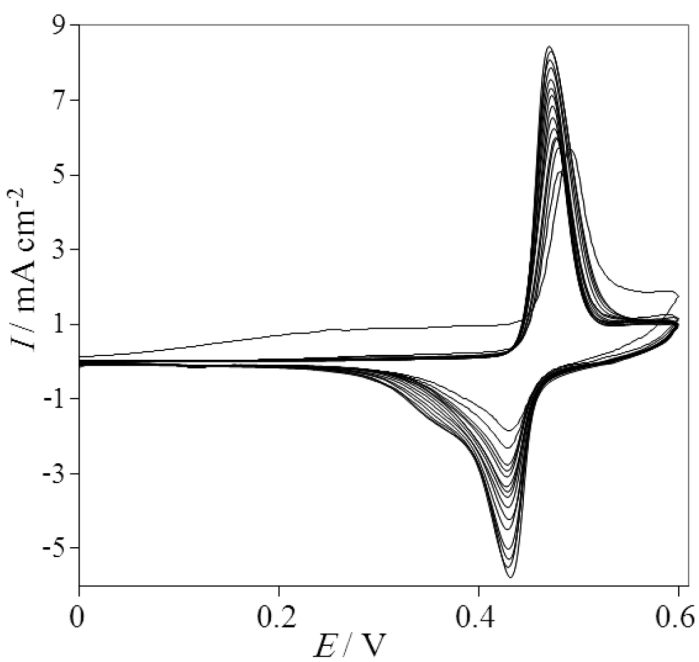

Fig. 1. Consecutive cyclic voltammogram of $\mathrm{Ni}$ oxidation in $1 \mathrm{M} \mathrm{NaOH}$ comprised of different sweep number $(1,2,3$, $4,5,6,10,15,20,25,30,35,40,45,50)$ at a scan rate of $100 \mathrm{mV} \mathrm{s}^{-1}$.

(CV) of a nickel electrode in $1 \mathrm{M} \mathrm{NaOH}$ solution recorded at a potential sweep rate of $100 \mathrm{mV} \mathrm{s}^{-1}$. In the first sweep a pair of redox peaks appear at 492 and 429 $\mathrm{mV}$ vs. $\mathrm{Ag} / \mathrm{AgCl}$ that are assigned to the $\mathrm{Ni}^{2+} / \mathrm{Ni}^{3+}$ redox couple according to:

$$
\mathrm{Ni}(\mathrm{OH}) 2+\mathrm{OH}^{-} \leftrightarrow \mathrm{NiOOH}+\mathrm{H}_{2} \mathrm{O}+\mathrm{e}^{-}
$$

In the subsequent cycles both the anodic and cathodic peaks shift negatively and stablize pointing to higher energies (potential) required for nucleation of $\mathrm{NiOOH}$ in the first cycle. The enhanced base line current of the first cycle is associated with the oxidation of $\mathrm{Ni}$ to $\mathrm{Ni}^{2+}$.

The current grows with the number of potential scans indicating the progressive enrichment of the accessible electroactive species $\mathrm{Ni}^{2+}$ and $\mathrm{Ni}^{3+}$ on or near the surface and stabilized after 50 cycles. After prolong cycling, the redox peak potential are stabilized at 472 and $427 \mathrm{mV}$ vs. $\mathrm{Ag} / \mathrm{AgCl}$ and a shoulder develops on cathodic peak at around $350 \mathrm{mV}$. The changes of the peaks position and also creation of a new reduction peak are likely due to the changes ${ }^{25)}$ in the crystal structures of the nickel hydroxide and the nickel oxyhydroxide constituents of the electrochemically formed surface film. It has been reported ${ }^{26,27)}$ that at the initial stages of electro-oxidation $\alpha-\mathrm{Ni}(\mathrm{OH})_{2}$ forms and is further slowly converted to the $\beta-\mathrm{Ni}(\mathrm{OH})_{2}$ form. ${ }^{28,29)}$

Fig. 2(a) presents typical CVs of a Ni electrode in 


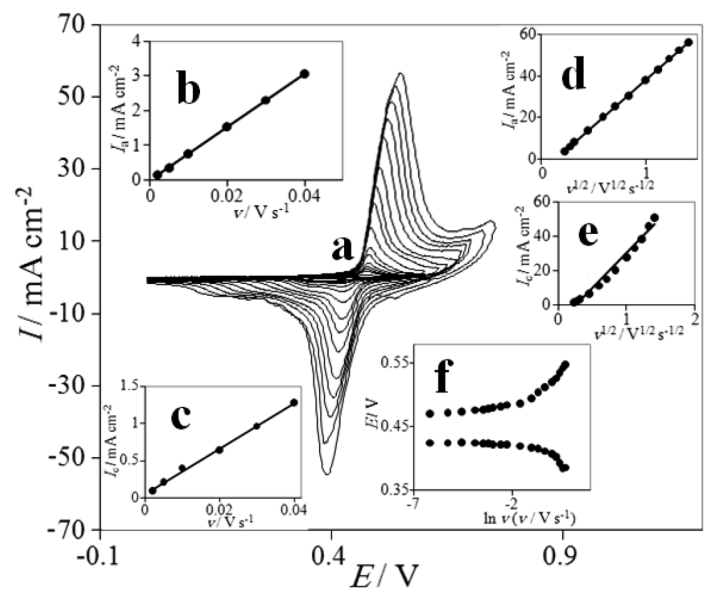

Fig. 2. (a) Typical cyclic voltammograms of a Ni electrode in $1 \mathrm{M} \mathrm{NaOH}$ in the potential sweep rates of $2,5,10,20$, $50,100,200,350,500,700,1000,1250,1500,1750$, $2000 \mathrm{mV} \mathrm{s}^{-1}$, (b) the dependency of anodic and (c)cathodic peak currents to the sweep rate at lower values $\left(2-40 \mathrm{mV} \mathrm{s}^{-1}\right)$. (d) The proportionality of anodic and (e) cathodic peak currents to the square roots of sweep rate at higher values $\left(50-2000 \mathrm{mV} \mathrm{s}^{-1}\right)$. (f) Plot of $E_{p} v s$. $\ln v$ for cyclic voltammograms depicted in panel (a) for anodic peaks (1) and cathodic peaks (2).

$1 \mathrm{M} \mathrm{NaOH}$ solution at various potential sweep rates of $2-2000 \mathrm{mV} \mathrm{s}^{-1}$. The peak current is proportional to sweep rates in the range of $2-40 \mathrm{mV} \mathrm{s}^{-1}$, Fig. 2(b) and (c), pointing to the electrochemical activity of the surface redox couple. ${ }^{30)}$ From the slope of these lines and using:

$$
I_{p}=\left(\frac{n^{2} F^{2}}{4 R T}\right) v A \Gamma^{*}
$$

where $\Gamma^{*}$ is the surface coverage of the redox species and $v$ being the potential sweep rate and taking average of both cathodic and anodic results, $\Gamma^{*}$ values of around $5.7 \times 10^{-8} \mathrm{~mol} \mathrm{~cm}{ }^{-2}$ has been derived that correspond to the presence of around 60 monolayers of surface species. In the higher potential sweep rates this dependency is of square root form, Figs. 2(d) and 2(e).

Laviron $^{31)}$ derived general expressions for the cyclic voltammetric response for the case of surface-confined electro-reactive species at small concentrations. The following simplified relations were proposed:

$$
E_{p a}=E^{0}+A \ln \left[\frac{1-\alpha}{m}\right]
$$

$$
\begin{aligned}
& E_{p c}=E^{0}+B \ln \left[\frac{\alpha}{m}\right] \\
& \ln k_{s}=\alpha \ln (1-\alpha)+(1-\alpha) \ln \alpha \\
& -\ln \left(\frac{R T}{n F v}\right)-\frac{\alpha(1-\alpha) n F \Delta E_{p}}{R T}
\end{aligned}
$$

where $A=R T /(1-\alpha) n F, B=R T / \alpha n F, m=(R T /$ $F)\left(k_{\mathrm{s}} / n v\right), E_{p a}$ and $E_{p c}$ are anodic and cathodic peak potential respectively, and $v$ the potential sweep rate, respectively. From these expressions, $\alpha$ can be determined by measuring the variation of the peak potential with respect to the potential sweep rate, and $k_{\mathrm{s}}$ can be determined for electron transfer between the electrode and surface modified layer by measuring the $E_{p}$ values. Fig. 2(f), shows the plot of $E_{p}$ with respect to the $\ln v$ from cyclic voltammograms recorded for Ni electrode in $1 \mathrm{M} \mathrm{NaOH}$ solution at potential sweep rates of 2-2000 $\mathrm{mV} \mathrm{s}^{-1}$ for anodic (1) and cathodic (2) peaks. It can be observed that for potential sweep rates of $200-1000 \mathrm{mV} \mathrm{s}^{-1}$ the values of $E_{p}$ are proportional to the logarithm of the potential sweep rate indicated by Laviron. Using the plot and Eq. (4), the values of $\alpha$ and $k_{s}$ were determined as 0.43 and $0.26 \mathrm{~s}^{-1}$, respectively.

Fig. 3 shows cyclic voltammograms of Ni electrode in $1 \mathrm{M} \mathrm{NaOH}$ solution in the absence (1) and presence (2) at of various concentrations of ethanol ranging from 0.1 to $1 \mathrm{M}$ and at a potential sweep rate of 10 $\mathrm{mV} \mathrm{s}^{-1}$. At Ni electrode, oxidation of ethanol appeared as a typical electrocatalytic response. The anodic charge increased with respect to that observed for the modified surface in the absence of ethanol and it was followed by decrease in the cathodic charge upon increasing the concentration of ethanol in solution. In the presence of $0.7 \mathrm{M}$ ethanol with the potential sweep rate of $10 \mathrm{mV} \mathrm{s}^{-1}$, the ratio of anodic to cathodic charge in the presence of ethanol was $98.5 / 1.5$ while in its absence it was $56 / 44$. Charge is obtained by integrating the anodic and cathodic peaks after the background correction.

The anodic current in the positive sweep was proportional to the bulk concentration of ethanol and any increase in the concentration of ethanol caused an almost proportional linear enhancement of the anodic current (Fig. 3(c)).

The decreased cathodic current that ensued the oxidation process in the reverse cycle indicated that the rate determining step certainly involves ethanol and 


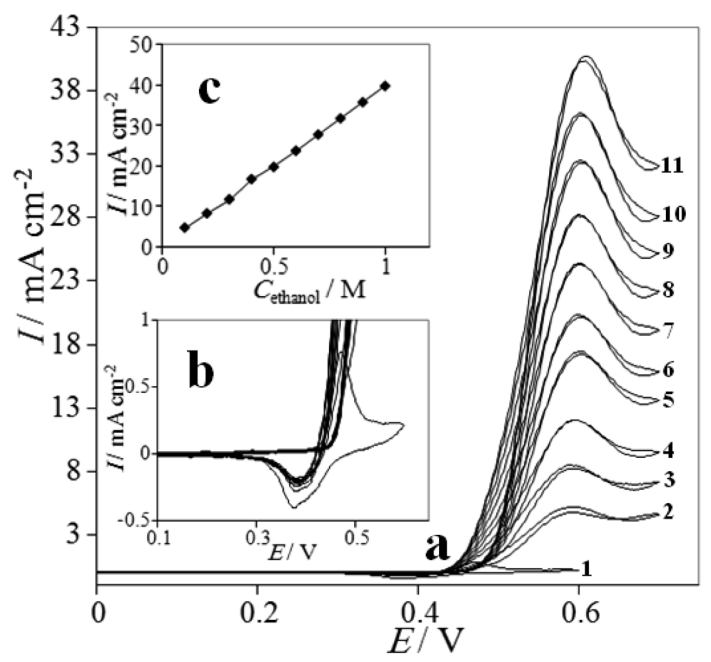

Fig. 3. (a) Cyclic voltammograms of the $\mathrm{Ni}$ electrode in $1 \mathrm{M} \mathrm{NaOH}$ solution in the absence (1) and the presence (2) $0.1 \mathrm{M}$; (3) $0.2 \mathrm{M}$; (4) $0.3 \mathrm{M}$; (5) $0.4 \mathrm{M}$; (6); $0.5 \mathrm{M}$; (7) $0.6 \mathrm{M}$; (8) $0.7 \mathrm{M}$; (9) $0.8 \mathrm{M}$; (10) $0.9 \mathrm{M}$; (11) $1 \mathrm{M}$ of ethanol in the solution. Potential sweep rate was $10 \mathrm{mV} \mathrm{s}^{-1}$. (b) Initial potential of ethanol oxidation. (c) Dependency of the anodic peak current on the concentration of ethanol in solution.

that it was incapable of reducing the entire high valent nickel species formed in the oxidation cycle.

The electrocatalytic oxidation of ethanol occurs not only in the anodic but also continues in the initial stage of the cathodic half cycle. Ethanol molecules adsorbed on the $\mathrm{Ni}^{2+}$ species are oxidized at higher potentials parallel to the oxidation of $\mathrm{Ni}^{2+}$ to $\mathrm{Ni}^{3+}$ species. The later process has the consequence of decreasing the number of sites for ethanol adsorption that along with the poisoning effect of the products or intermediates of the reaction tends to decrease the overall rate of ethanol oxidation. Thus, the anodic current passes through a maximum as the potential is anodically swept. In the reverse half cycle, the oxidation continues and its corresponding current goes through the maximum due to the regeneration of $\mathrm{Ni}$ (II) species that are active sites for the adsorption of ethanol as a result of removal of adsorbed intermediates and products. Surely, the rate of ethanol oxidation as signified by the anodic current in the cathodic half cycle drops as the unfavorable cathodic potentials are approached.

Fig. 4 shows the cyclic voltammograms of Ni electrode in $1 \mathrm{M} \mathrm{NaOH}$ in presence of $0.5 \mathrm{M}$ ethanol at a scan rate of $50 \mathrm{mV} \mathrm{s}^{-1}$ for 300 cycles. It is observed that the current density of electrooxidation of ethanol

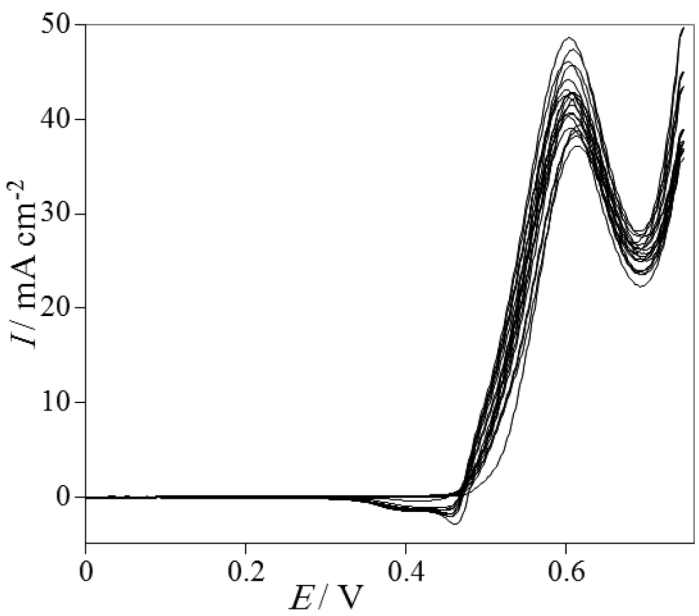

Fig. 4. Repeated cyclic voltammograms of $0.5 \mathrm{M}$ ethanol oxidation on $\mathrm{Ni}$ electrode at $50 \mathrm{mV} \mathrm{s}^{-1}$, cycle number: 1,5 , $10,20,50,100,150,200,250,300$.

is almost constant in 300 cycles due to the stability of electrocatalyst in this cycle number and indicating that ethanol reacted with the surface and no poisoning effect on the surface was observed.

Cyclic voltammograms of $\mathrm{Ni}$ in the presence of $0.5 \mathrm{M}$ ethanol at various potential sweep rates and the proportionality of anodic peak currents to the square root of sweep rates in a range of 2 to $500 \mathrm{mV} \mathrm{s}^{-1}$ are illustrated in Fig. 5(a), (b), respectively. The cathodic peak was not observed in low scan rates, but appeared upon increasing the sweep rate. The phenomenon indicates that the electrooxidation of nickel species to higher valence state is much faster than the catalytic oxidation of ethanol. This reveals that the oxidation of ethanol on Ni may belong to a slow process. At higher scan rates a new oxidation peak observed for ethanol oxidation at a potential much more positive than that of the oxidation of $\mathrm{Ni}(\mathrm{OH})_{2}$ potential. Meanwhile, the anodic peak currents that are linearly proportional to the square root of scan rate (Fig. 5(b)) suggest that the overall oxidation of ethanol at this electrode is controlled by the diffusion of ethanol from solution to the surface redox sites. From the slope of the straight line the diffusion coefficient of ethanol was obtained as $2 \times 10^{-7} \mathrm{~cm}^{2} \mathrm{~s}^{-1}$. Moreover, a plot of the scan ratenormalized current $\left(I / v^{1 / 2}\right)$ with respect to scan rate (Fig. 5(c)) exhibited a typical shape of an electrochemical-chemical (EC) catalytic process. ${ }^{32}$ The value of electron transfer coefficient for the reaction which is totally irreversible-diffusion controlled can be 


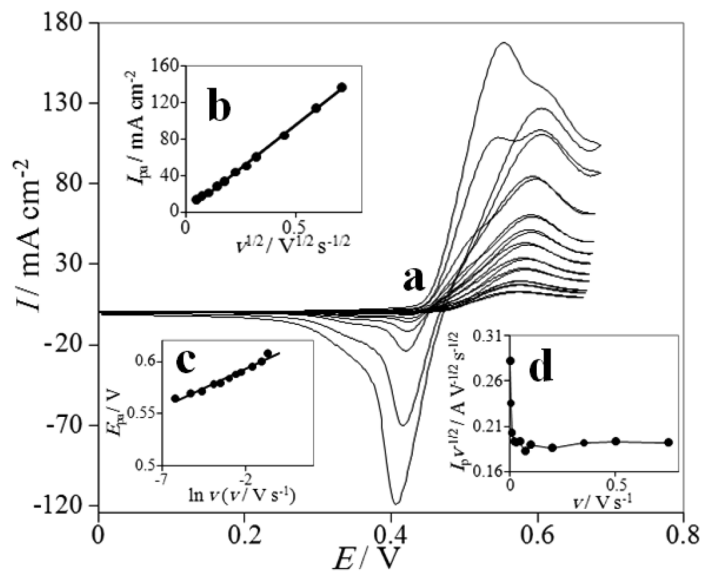

Fig. 5. (a) Typical cyclic voltammograms of the $\mathrm{Ni}$ in $1 \mathrm{M}$ $\mathrm{NaOH}$ in the presence of $0.5 \mathrm{M}$ ethanol at various potential sweep rates of $2,5,10,20,30,40,50,75,100,200,350$ and $500 \mathrm{mV} \mathrm{s}^{-1}$. (b) Dependence of anodic peak current during the forward sweep on the square roots of sweep rate. (c) The anodic current function $\left(I / i^{1 / 2}\right)$ vs. potential sweep rate $v$. (d) Dependence of the peak potential on $\ln v$ for the oxidation of ethanol at $\mathrm{GC} / \mathrm{Ni}$ electrode.

obtained from the following equation ${ }^{33}$ :

$$
E_{P}=\left(\frac{R T}{n \alpha F}\right) \ln v+\text { constant }
$$

Using the dependency of anodic peak potential on the natural logarithm of the potential sweep rate (Fig. 5(d)), the value of electron transfer coefficient was obtained as 0.87 .

High current density was observed in presence of ethanol in comparison to the $\mathrm{Ni}(\mathrm{OH})_{2}$. Also a new oxidation peak was obtained for ethanol oxidation at a potential much more positive than that of the oxidation of $\mathrm{Ni}(\mathrm{OH})_{2}$ potential. According to these data it can be assume that partly of the current is due to ethanol oxidation by $\mathrm{NiOOH}$ due to the disappearance of the $\mathrm{NiOOH}$ reduction peak in the negative sweep, Eq. (7) $\&(8)$, and partly of the current is due to ethanol oxidation on the surface of oxide or within (inside) the oxide layer, Eq. (9) \& (10).

The redox transition of nickel species present in the film is:

$$
N i(I I) \stackrel{\mathrm{v}_{1}}{\longleftrightarrow} N I(I I I)+e^{-}
$$

and ethanol is oxidized on the modified surface via the following reaction:

$$
\mathrm{Ni}^{3+}+\text { ethanol } \stackrel{\mathrm{v}_{2}}{\longrightarrow} \mathrm{Ni}^{2+}+\text { intermediate }
$$

$$
\mathrm{Ni}^{3+}+\text { intermediate } \stackrel{\mathrm{V}_{3}}{\longrightarrow} \mathrm{Ni}^{2+}+\text { products }
$$

where $\mathrm{Ni}^{3+}$ sites are regenerated by the power source and on the $\mathrm{Ni}^{3+}$ oxide surface by direct electrooxidation $^{34,35}$

$$
\begin{aligned}
& \mathrm{Ni}^{3+} \text { - ethanol } \stackrel{\mathrm{v}_{4}}{\longrightarrow} \mathrm{Ni}^{3+}-\text { intermediate }+3 \\
& \mathrm{Ni}^{3+} \text { - intermediate } \stackrel{\mathrm{v}_{5}}{\longrightarrow} \mathrm{Ni}^{3+} \text { - products }+\mathrm{e}
\end{aligned}
$$

Eqs. (7) \& (8) is according to Fleischmann mechanism and in Eqs. (9) \& (10), $\mathrm{Ni}^{3+}$ used as active surface for ethanol oxidation. Observation of a new oxidation peak for ethanol oxidation at a potential much more positive than that of the oxidation of $\mathrm{Ni}(\mathrm{OH})_{2}$ potential is according to Eqs. (9) \& (10). According to above equation the Faradaic current density can be written as:

$$
I_{F}=\left(v_{1}+v_{4}+v_{5}\right) F
$$

Setting the working electrode potentials to desired values, the measurement of the catalytic rate constant as well as the diffusion coefficient of ethanol was performed under chronoamperometric regime. Fig. 6(a) shows double steps choronoamperograms for the $\mathrm{Ni}$ in the absence (1) and presence (2-6) of ethanol over a concentration range of 0.1 to $0.9 \mathrm{M}$ with an applied potential steps of 620 and $300 \mathrm{mV}$, respectively. Plotting of net current with respect to the mines reverse

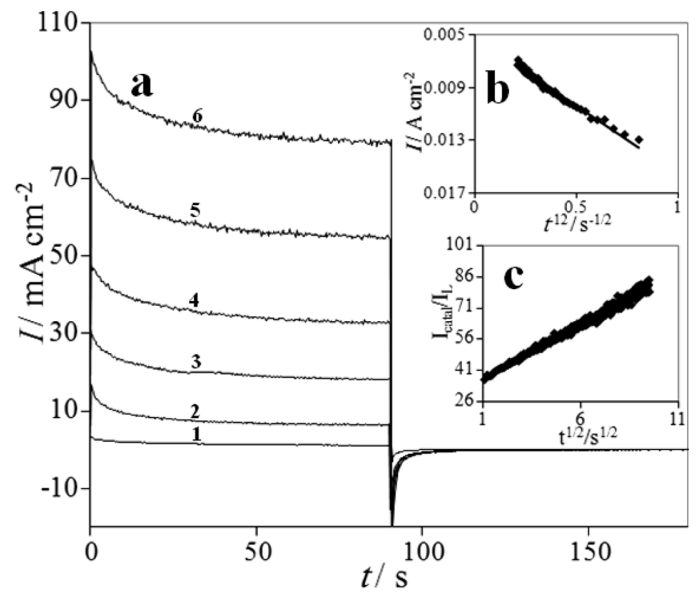

Fig. 6. (a) Double steps chronoamperograms of $\mathrm{Ni}$ electrode in $1 \mathrm{M} \mathrm{NaOH}$ solution with different concentrations of ethanol of: (1) $0 \mathrm{M}$, (2) $0.1 \mathrm{M}$, (3) $0.3 \mathrm{M}$, (4) $0.5 \mathrm{M}$, (5) $0.7 \mathrm{M}$ and (6) $0.9 \mathrm{M}$. Potential steps were $620 \mathrm{mV}$ and $300 \mathrm{mV}$, respectively. (b) Dependency of transient current on $t^{1 / 2}$. (c) Dependence of $I_{\text {catal }} / I_{L}$ on $t^{1 / 2}$ derived from the data of chronoamperograms of 1 and 6 in panel (a). 
square roots of time, after removing the background current presents a linear dependency (Fig. 6(b)). The dominance of a diffusion-controlled process is evident. Using the slope of this line in Cottrell equation $^{30)}$ :

$$
I=n F A D^{1 / 2} C^{*} \pi^{-1 / 2} t^{-1 / 2}
$$

the diffusion coefficient of ethanol has been obtained to be $1 \times 10^{-7} \mathrm{~cm}^{2} \mathrm{~s}^{-1}$ which is in good agreement with value with the value obtained by cyclic voltammetry. The current is also negligible when potential is stepped down to $320 \mathrm{mV}$, indicating the irreversibility of ethanol oxidation process.

Choronoamperometry can also be used for the evaluation of the catalytic rate constant ${ }^{36}$ )

$$
\frac{I_{c a t}}{I_{L}}=\gamma^{1 / 2}\left[\pi^{1 / 2} \operatorname{erf}\left(\gamma^{1 / 2}\right)+\frac{\exp (-\gamma)}{\gamma^{1 / 2}}\right]
$$

where $I_{c a t}$ and $I_{L}$ are the currents of the $\mathrm{Ni}$ in the presence and absence of ethanol and $\gamma=k C^{*} t$ is the argument of the error function. $k$ is the catalytic rate constant, $C^{*}$ is bulk concentration of ethanol and $t$ is elapsed time (s). In the cases where $\gamma>1.5, \operatorname{erf}\left(\gamma^{1 / 2}\right)$ is almost equal to unity and the above equation simplifies to:

$$
\frac{I_{\text {cat }}}{I_{L}}=\gamma^{1 / 2} \pi^{1 / 2}=\pi^{1 / 2}\left(k C^{*} t\right)^{1 / 2}
$$

From the slope of the $I_{\text {cat }} / I_{L}$ vs. $t^{1 / 2}$ plot, presented in Fig. 5(c) the mean value of $k$ for the concentration range of $0.1 \mathrm{M}$ to $0.9 \mathrm{M}$ of ethanol was obtained as $9.64 \times 10^{3} \mathrm{~cm}^{3} \mathrm{~mol}^{-1} \mathrm{~s}^{-1}$.

In comparison with recently published work for ethanol electrocatalytic oxidation on $\mathrm{Pt}, \mathrm{Pd}, \mathrm{Au}$ and its alloys, ${ }^{37-39)}$ higher oxidation current density and catalytic activity was obtained for nickel modified $\mathrm{NiOOH}$ electrode.

\section{Conclusions}

The nickel oxide film was formed electrochemically on nickel electrode in a regime of cyclic voltammetry and tested for electrooxidation of ethanol in alkaline media. The modified electrode showed electrocatalytic activity for the oxidation of ethanol at around 600 $\mathrm{mV}$ vs. $\mathrm{Ag} / \mathrm{AgCl}$. The Ni modified nickel oxyhydroxide electrode exhibited large response current for oxidation of ethanol. A kinetic model was developed and using the methods of cyclic voltammetry, choronoamperometry, the kinetic parameters such as transfer coefficient $(\alpha)$, the catalytic reaction rate constants $(k)$, and the diffusion coefficient of ethanol in the bulk of solution were determined.

\section{References}

1. H. Uchida, Y. Mizuno and M. Watanabe, J. Electrochem. Soc. 149, A682 (2002).

2. W. C. Choi, J. D. Kim and S. I. Woo, Catal. Today 74, $235(2002)$.

3. Z. B. Wang, G. P. Yin and P. F. Shi, Carbon 44, 133 (2006).

4. C. Lamy, E. M. Belgsir and J.-M. Leger, J. Appl. Electrochem. 31, 799 (2001).

5. E. V. Spinace, A. O. Neto and M. Linardi, J. Power Sources 124, 426 (2003).

6. W. J. Zhou, S.Q. Song, W. Z. Li, Z. H. Zhou, G. Q. Sun, Q. Xin, S. Douvartzides and P. Tsiakaras, J. Power Sources 140, 50 (2005).

7. Z. B. Wang, G. P. Yin, J. Zhang, Y. C. Sun and P. F. Shi, J. Power Sources 160, 37 (2006).

8. G. A. Camara, R. B. de Lima and T. Iwasita, Electrochem. Commun. 6, 812 (2004).

9. C. Lamy, S. Rousseau, E. M. Belgsir, C. Coutanceau, and J.-M. Leger, Electrochim. Acta 49, 3901 (2004).

10. A. O. Neto, M. J. Giz, J. Perez, E. A. Ticianelli and E. R. Gonzalez, J. Electrochem. Soc. 149, A272 (2002).

11. J. M. Leger, S. Rousseau, C. Coutanceau, F. Hahn and C. Lamy, Electrochim. Acta 50, 5118 (2005).

12. J. P. I. Souza, S. L. Queiroz, K. Bergamaski, E. R. Gonzalez and F. C. Nart, J. Phys. Chem. B 106, 9825 (2002).

13. T. Iwasita and E. Pastor, Electrochim. Acta 39, 531 (1994).

14. T. Iwasita, R. Dalbeck, E. Pastor and X. Xia, Electrochim. Acta 39, 1817 (1994).

15. H. Hitmi, E. M. Belgsir, J.-M. Leger, C. Lamy and R. O. Lezna, Electrochim. Acta 39, 407 (1994).

16. J. Shin, W. J. Tornquist, C. Korzeniewski and C. S. Hoaglund, Surf. Sci. 364, 122 (1996).

17. X. H. Xia, H. D. Liess and T. Iwasita, J. Electroanal. Chem. 437, 233 (1997).

18. J. F. E. Gootzen, A. H. Wonders, A. P. Cox, W. Visscher and J. A. R. Van Veen, J. Mol. Catal. A: Chem. 127, 113 (1997).

19. R. Ianniello, V. M. Schmidt, J. L. Rodriguez and E. Pastor, J. Electroanal. Chem. 471, 167 (1999).

20. S.-M. Park, N. Chen and N. Doddapaneni, J. Electrochem. Soc. 142, 40 (1995).

21. J.-W. Kim and S.-M. Park, J. Electrochem. Soc. 146, 1075 (1999).

22. J.-W. Kim and S.-M. Park, J. Electrochem. Solid State Lett. 3, 385 (2000). 
23. J. W. Kim, S. M. Park, J. Korean Electrochem. Soc. 8, $117(2005)$

24. M. Jafarian, F. Forouzandeh, I. Danaee, F. Gobal and M. G. Mahjani, J. Solid State Electrochem. 13, 1171 (2009).

25. A. A. El-Shafei, J. Electroanal. Chem. 471, 89 (1999).

26. I. Danaee and M. Jafarian, A. Mirzapoor, F. Gobal, M.G. Mahjani, Electrochim. Acta 55, 2093 (2010).

27. F. Hahn, B. Beden, M. J. Croissant and C. Lamy, Electrochim. Acta 31, 335 (1986).

28. J. Desilvestro, D. A. Corrigan and M. J. Weaver, J. Electrochem. Soc. 135, 885 (1988).

29. I. Danaee, M. Jafarian, F. Forouzandeh, F. Gobal and M. G. Mahjani, Electrochim. Acta (2008) 53, 6602.

30. A. J. Bard and L. R. Faulkner, Electrochemical Methods, fundamentals and applications, Wiley, New York, 2001, p. 591.

31. E. Laviron, J. Electroanal. Chem. 101, 19 (1979).
32. R. S. Nicholson and I. Shain, Anal. Chem. 36, 706 (1964).

33. J. A. Harrison and Z. A. Khan, J. Electroanal. Chem. 28 , 131 (1970).

34. I. Danaee, M. Jafarian, F. Forouzandeh, F. Gobal and M. G. Mahjani, Int. J. Hydrogen Energy 34, 859 (2009).

35. I. Danaee, M. Jafarian, F. Forouzandeh, F. Gobal and M. G. Mahjani, J. Phys. Chem. B 112, 15933 (2008).

36. I. Danaee, M. Jafarian, F. Forouzandeh, F. Gobal and M. G. Mahjani, Int. J. Hydrogen Energy 33, 4367 (2008).

37. C. Li, Y. Su, X. Lv, H. Shi, X. Yang and Y. Wang, Mater. Lett. 69, 92 (2012).

38. X. Han, D. Wang, D. Liu, J. Huang and T. You, J. Colloid Interface Sci. 367, 342 (2012).

39. G. Hu, F. Nitze, H. R. Barzegar, T. Sharifi, A. Mikołajczuk, C.-Wai Tai, A. Borodzinski and T. Wagberg, J. Power Sources 209, 236 (2012). 